\title{
Collaborative Learning as a Vehicle for Learning about Collaboration
}

\author{
David A Banks \\ University of South Australia, Adelaide, Australia
}

\author{
david.banks@unisa.edu.au
}

\begin{abstract}
This paper explores the development and delivery of a Masters course titled 'Collaboration and ECommerce'. The course examines a variety of issues relating to E-Commerce with the major focus being upon collaborative aspects of web-related business activities. The aim of the course is to lead students to engage in actual collaborative processes and so to provide them with practical experience to support the theoretical aspects of the subject. The paper outlines the issues behind the design of the learning structure that was used to promote both intra-group and inter-group collaborative action. Although the course is currently run in face-to-face mode with no web support it had to be designed in such a way that the learning structures and processes would translate to a web-enabled form for future operation.
\end{abstract}

Keywords : IS Education, collaborative learning, e-commerce

\section{Introduction}

The course (subject) 'Collaboration and E-Commerce' discussed in this paper is part of a suite of Masters programs within the School of Accounting and Information Systems and was first delivered in 2000, Term 2. This paper focuses upon the version that was delivered in 2002, Term 2. The course examines collaborative activities in the context of E-Commerce, or more generally in the Web environment. The basic premise of the course is that Internet and the Web can be viewed as both triggers for change in business paradigms and also as enabling mechanisms to support those changes. That is, the potential problems and opportunities that are raised as a result of the ability to have collaborative teams based in different time zones and cultures can be addressed by using the tools that the new environment itself offers. The major focus of this course is upon broad collaboration issues and students are advised that this is not specifically an E Commerce course and that there is NO practical focus upon designing or building web pages.

The course was originally intended to explore issues relating to collaborative aspects of web related business environments with the long-term aim of introducing a variety of software tools to facilitate the development of a web-based collaborative environment within which learning could take place. In practice the need for a number of changes in the course structure, delivery pattern and available software has delayed the practical development of the electronic aspects of the collaborative learning approach. The

Material published as part of these proceedings, either on-line or in print, is copyrighted by Informing Science. Permission to make digital or paper copy of part or all of these works for personal or classroom use is granted without fee provided that the copies are not made or distributed for profit or commercial advantage AND that copies 1) bear this notice in full and 2) give the full citation on the first page. It is permissible to abstract these works so long as credit is given. To copy in all other cases or to republish or to post on a server or to redistribute to lists requires specific permission from the publisher at Publisher@InformingScience.org focus has therefore been upon the introduction of a learning approach that is soundly based on collaborative learning principles and which can incorporate electronic collaborative support tools in the longer term. 


\section{Collaborative learning}

The learning process for this course is firmly anchored in inter and intra group-based collaborative activities. Students work in small groups (typically five) on a designated task but also act in a collaborative manner with other groups in the course. The member of staff is yet another element in the overall collaborative learning activity. The only individual work in this course is in the examination. This is included in the assessment program to ensure that students have an opportunity to demonstrate individual capabilities in addition to the collaborative skills used in the group work.

Small group cooperative learning can be defined as a classroom environment where individual students interact with one another in small groups while working together on academic tasks to attain a common goal (Parker, 1984; Johnson and Johnson, 1986). The benefits of such learning suggest significant gains in a number of areas, including broad academic achievement, social relationships, self-esteem, crosscultural/cross racial relationships and attitudes towards schooling and learning (Parker, 1984; Davidson 1990). Vygotsky (1978) suggests that students are capable of performing at higher intellectual levels when asked to work in collaborative situations than when asked to work individually. The key elements of collaborative learning are usually identified as positive interdependence, face-to-face promotive interaction, individual and group accountability, social skills and group processes. (Johnson, Johnson and Smith, 1991)

- Positive Interdependence: The learning environment is structured in such a way that students must share information and carry out work that directly affects the work and success of others. The resources of all group members are required to achieve a goal that could not be achieved by individuals.

- Face-to-Face Promotive Interaction: Students need to help, encourage, and support each other's efforts to learn because they depend on each other.

- Individual and Group Accountability: Each individual's performance is assessed in terms of both their individual contribution to the group and the overall group performance.

- Social Skills: To work effectively together, students must learn to use appropriate social skills, e.g., leadership, decision- making, trust-building, communication, conflict-management.

- Group Process To improve the group process, students need to actively and continually analyse how well they are achieving their goals and maintaining effective working relationships

The key structure that supports the implementation of elements above is the assignment pattern that forms a focus around which these elements can be developed. An assignment activity was required that required students to carry out a reasonably large and intensive task in a short time scale so that all group members would need to function effectively as a unit to complete the task. It was also felt, within the overall context of a Masters program, that the task should involve research, critical thinking and be authentic in the sense that it should be a 'real' task rather than one invented just for assessment. The task chosen was the development and co-writing of a conference-style paper, the stages of development being based upon typical conference development, submission and presentation process. Each group had their draft papers reviewed at least twice by other groups in the course as well as by the staff member. The quality of the reviews was also assessed by the member of staff. The objective here was to focus students on the critical review of papers in order that they could both improve the papers of other groups and, at the same time, hopefully bring the same critical thinking to their own papers.

At the end of the course a peer review was conducted using an electronic hand-held group process support system. The criteria for the peer review process were identified by the students as representing issues that they felt were significant for effective collaboration. Each student group assessed each member 
of the group in turn using the keypad system and at the end of the review session the group was shown the results and invited to comment.

\section{The Course in Practice}

The 2002 Term 2 course started with fifty students with a wide range of age, experience, cultural background and language skills. Both genders are represented in almost equal numbers, with a slight bias towards males. Groups of five students were formed during the later part of the first session. The choice of a group size of five was based on both theoretical and pragmatic thinking. Literature suggests that many people find groups of five comfortable and that smaller groups (typically three members) contain less diversity and may lack divergent thinking skills and varied expertise to ensure that all members participate in decision- making (Rau and Heyl, 1990). The choice of five members also allows for loss of one member of the group early in the course without severe impact upon the ability of the remainder to complete the task. Finally, the assessment pattern was complex and required fast turn-round of large volumes of material and the member of staff felt that logistically ten groups of five would be manageable.

The allocation to groups was under the control of the member of staff and was carried out by first putting students into Program groups (i.e. those studying an E Business stream, those studying consultancy, marketing and so on). The next step was to select members from each of the groups to form a heterogeneous group, not only on the basis of program but also on a rough age/gender/nationality mix. Normally the author would let students self-select groups but it was felt that deliberate forced mixing in the way described would maximise diversity and also avoid the effects of Groupthink (Janis, 1971) that can occur in some long-established student groups. The 2001 delivery of the course had received mixed feedback about the group formation process, ranging from '... being placed in groups rather than being able to choose our own penalised us I think. We should be able to choose who we work with as many students have different expect ations of what they would like to gain from subjects', through to 'The good part of this subject, although many would beg to differ, was being put into groups not of our choosing and seeing some of the problems that occur in a collaborative setting. It was a good way to network with some other the students outside our program.' For the latest delivery more time was spent explaining what the benefits of such deliberate mixing could be and this seems to have helped students more readily accept the approach.

Each group was given the opportunity to meet, chat, develop communication strategies and also to select the two topics that would form the first part of the task. A list of twenty-two topics was provided and the groups were able to select two that they felt would be of interest to their group. Once selections were made these were deleted from the list, thus ensuring that by the end of the session each group had two unique topic areas to work on. The topic list was drawn from a variety of impending E Commerce conferences and was chosen to cover what were hoped would be stimulating or novel areas as well as being significant areas that would be explored during the actual course. The list presented was:

1. Procurement, bidding, auctions

2. Information \& communication platforms, mobile agents, unified messaging

3. Legal, social, cross-cultural issues

4. Innovative government services for the citizen

5. Innovative installations: CSCW and the arts

6. Methodologies and tools for design and analysis of collaborative practices

7. Working with and through collections of heterogeneous technologies

8. Innovative technologies and architectures to support group activity, awareness and tele-presence

9. Required skills for someone working in a collaborative E-Commerce environment (B2B, B2C, $\mathrm{G} 2 \mathrm{C}$, etc).

10. Societal Integration of Business Processes 
11. Project Management, Groupware, and Workflow

12. Virtual Reality

13. Modelling and Simulation

14. Intra organisational communications

15. Privacy Issues for Electronic Commerce

16. E Health

17. Authoring environments

18. e-Business in developing countries

19. Multilingual access

20. International collaborative programs

21. Mobile devices with PDA/WAP/3G

22. Knowledge discovery \& data mining

Students were advised that these were not titles but rather areas within which they were free to develop their own focus and they were encouraged to take imaginative and creative approaches wherever possible. Considerable time was spent with each group suggesting perspectives that they may wish to consider and sometimes suggesting starting points for literature. Some of the titles that eventuated included:

1. Implementing collaborative technologies in the e-commerce environment: is it worthwhile?

2. How knowledge discovery and data mining can support collaboration - or can it?

3. The barriers to effective collaboration and e-commerce for companies utilising e-marketplaces for procurement

4. E-commerce and the English Language

5. Why the internet fails to provide an appropriate mechanism to foster international collaborative programs between developed and developing countries

6. E-business from a developing country's perspective

7. The potential collaborative and e-commerce dystopia: argument for the management of future business process technologies and their societal impact

8. Developing countries and colonialism via E-business

9. The collaborative domain: a balance of approaches

10. Virtual Urbanisation of community collaboration and e-commerce: The changing face of business processes and societies

The third week saw the delivery of the first piece of work. This comprised a 250 word draft for each of the group's topics from each group member, plus two 500 word drafts, one for each chosen topic that represented a combination of each individual member's ideas. Three copies of each group draft were handed in at the start of the session. One was retained by the member of staff, along with each individual members work and the two other drafts were distributed to other groups for review. This proved to be a complex and rather messy process, despite a carefully planned approach using folders with each groups number clearly printed on it. However, each group eventually left the session with four papers to review for the following week. Once again the brief was to review the papers as individual members (200 words) and then to share their thoughts and produce a single group review document (400 words) for each paper.

Each group was issued with a set of guidelines to help them in the review process as well as copies of actual conference paper reviews, both positive and negative, that the author had submitted to a number of conferences. The guidelines were synthesised from a number of real conferences, with the purpose of the review being indicated as: 
- To provide authors with useful, timely feedback through a critical and constructive review process

- To indicate to authors where the strengths and weaknesses lie in their work

- To suggest areas of improvement and indicate literature that may usefully inform the authors

- To suggest ways in which the paper can be made more novel or interesting, or suggest areas, themes or arguments in the paper that may be usefully expanded upon

- To suggest ways in which a strong balance of argument can be developed

- To identify any literature within the paper that offers only weak support for the key argument

- To suggest structural arrangements that will help the authors 'tell a story' in a clear and convincing way

The students were asked to view the papers as having been submitted for a conference titled 'Collaboration and E Commerce' and to decide if the paper lay within the frame of the conference. An overall rating was asked for using the scale of:

5 Excellent draft

4 Some minor weaknesses but essentially good

3 Some strong points but significant weaknesses

2 Yet another paper about ... (YAPA)

1 Poor - do not see where the paper is going

Finally the students were asked to indicate if they felt that the paper would be acceptable for a conference titled "Collaboration and E Commerce" using the simple comments:

- Yes, with no reservations

- Yes, subject to minor changes

- Yes, subject to major revisions

- No, reject

For the initial drafts the students were advised that they did not need to comment on typographical errors, grammar, referencing style or other details but to concentrate upon the story, the references used, credibility, novelty and so on.

The quality of reviews was excellent and carried out in a supportive but critical way. There was clear evidence that the work had been carefully read and many useful suggestions were made. There was no evidence at all of any unreasonably negative or unwarranted comments and two students commented that 'The feedback from other groups via the review process was a tremendous help'. One student group initially felt quite upset that the comments they received were rather negative. They had written a somewhat descriptive and technical treatise under the 'Mobile devices with PDA/WAP/3G' heading and the reviewers all felt that this would lie outside the frame of the intended conference. The recognition that three different sets of reviewers all felt the same way eventually convinced them that they needed to re-think the paper and that the negative review was about the paper rather than themselves as individuals.

The outcome of the review process was that the groups should select just one paper from the initial two and to develop this into the final paper. This selection process was guided by the reviews but the groups were advised that if they still felt that a paper that had received poor reviews was still their preferred 
choice they could still stay with it. The chosen paper was further developed until week six when it was again handed in as a 2000 word paper for review by the member of staff and two other groups. The new review groups were not the same as for the previous drafts. Again the reviews were excellent showing insight, thoughtfulness and support for the other groups. The students received this final review at the start of week seven, leaving three weeks to prepare the final 3000 word paper which was marked by the member of staff only. Week eight was used to carry out the electronic peer review session. In week ten (the final week) the students gave a conference-style presentation to all groups. This ensured that all students were able to engage with the topics of all other groups, thus avoiding any problems of perceived isolation by groups in their own, or a limited selection of, the overall topics covered in the course.

The examination was carried out in week eleven. This comprised four questions, the first being compulsory and designed to lead the students to reflect on their experiences and to consider whether or not they felt that the collaborative working had led to improved outcomes for them. The remaining multi-part questions, of which they chose two from three, were open-ended questions of the style 'How can the idea of 'reality as a social construct' be related to 'trust' in the context of web-based collaborative activities?'

\section{Student Feedback}

The compulsory examination question that elicited students' views of the benefits, or otherwise, of collaborative working provided some useful insights. Of course, these are responses to an examination question and the writers may have been trying to find the 'right' answer to satisfy the examiner. However it is felt that they still offer value in considering the outcome of a process of exposing the students to a quite intensive collaborative learning experience. Informal conversations supported the written responses from the examination question. Thirty-four students felt that working as part of a collaborative group had helped them gain higher marks, with thirteen indicating that they did not feel that this process generated higher marks for them.

For positive interdependence to have been achieved the task should have been such that students felt that they could not have achieved the goals as individuals and that all group resources needed to be used. Comments from students that suggest a degree of positive interdependence include:

- Can share the work among the group allowing individual focus on specific aspect of processdivision of labour

- Workload was heavy and I don't think I could have completed the task by myself.

- $\quad$ The broad scope of the subject and short time scale meant that the team was able to cover more areas.

- The end product was far in advance of what an individual could achieve in the short period of the course

- It would have been impossible for me to do the research for the first two draft papers by myself with the time available so we shared this load. And, surprisingly, we turned up different information even though we were all looking at the same topic - this led to better ideas, in both quality and quantity.

Signs of students helping and supporting each other (face-to-face promotive interaction) are suggested by:

- Mixed skills in the group mean any deficiencies in own skills can be compensated for by others

- Opportunity to share load and deal with unexpected events that may have damaged an individuals work 
- Responsibility as a member of a group means that you are more motivated to meet deadlines

Evidence for the development or enhancement of Social skills appears to be represented by:

- Discussion and argument can lead to deeper understanding and a richer outcome

- I believe that I would have achieved the same mark if I had worked by myself but it would have required more effort on my part. However the depth of research carried out by the group was greater that I could have achieved as an individual led to a broader range of discussion.

Group process gains can be found in such comments as:

- Helps generate ideas that I, as an individual, would never have thought of

- The work was drawn from multiple perspectives and led to a much better outcome

- Can share ideas or views based on experience, culture and belief and gain similar from them leading to stimulation of new ideas

- Diversity in age, gender, cultural background and experience all strengthened the group

- Local [Australian] students can help us [trans-national students] to write better English

- As an overseas student English will always be the first obstacle for me. Working in a group allows me to learn more words and a more accurate writing style. I have learnt the confidence to speak up and express my views.

Comments relating to individual and group accountability were not in evidence but much of this emerged in the de-briefs that followed the electronic peer review sessions. It was felt that the peer review session did indicate the relative contributions and those that were slightly weak were willing to acknowledge this. Students commented that the use of the electronic feedback system would have provided the groups with useful insights to their dynamics had it been used a number of times in the earlier stages of the course. This possibility will be explored in a future version of the course.

Thirteen students felt that the collaborative group-work had not improved their potential marks and offered a variety of reasons to support this view. Several comments related to the overhead required to coordinate groups, problems with dominant members and to differing levels of commitment:

- There were several visions of the end product and dominant group members 'pushed' their ideas.

- The leader was too strong and took us in directions we did not feel were right

- Some dysfunctional conflict due to role ambiguity, lack of early determination or allocation of roles

- I am not sure I gained higher marks but the time required to coordinate activities was immense

- Unresolved differences led to tensions

- Differences in aspirations of members (some aiming for D, some for a Pass) led to low cohesion

- Some people thought that when they had finished 'their' part of the work they didn't need to do any more

- Conflict and resentment in the group and dominant leadership did not produce the hoped for benefits. We had 4 nationalities in the group as well as both genders and a wide age range. Some nationalities were polite, deferential and quiet, and language was a problem.

The issue of language skills was specifically mentioned by some students: 
- Low levels of language competency of some students meant that time was wasted explaining things or re-writing materials from other group members

- Different writing styles and English skills led to considerable time spent re-writing

The difficulties with English are real and are perhaps indicated by this (verbatim) comment:

- Some student have facing language problem for their assignment. The good language can more stronger the idea.

It should be noted, however, that the majority of groups accepted the varying levels of English as just another factor in collaboration and simply dealt with it as part of the group process.

Other comments suggested that some students would simply have preferred to work by themselves because working in groups detracted from the task in hand or did not provide sufficient control over the task:

- My strengths are in my ability to create and generate ideas which I think have potential value. Working collaboratively limited my ability to work at my own pace and creative ability.

- As an individual I would have remained focussed on the task - there was too much compromising at the start of the task

- There was conflict in the group and I did not feel that the project was mine

- I would have had total control of the final document and therefore would have received a higher mark

Bringing together students with different personality types, background cultures, cognitive styles and expectations about their roles in an environment where there may be new relationships with peers, staff and unfamiliar course processes naturally produce tension. (Miller, Trimbur and Wilkes, 1994) However the active discussion of such tensions through the lectures, seminars and collaborative group work has hopefully helped to reduce these tensions, or at least allowed them to be acknowledged in an honest and open way.

\section{Conclusion}

This course offered students an opportunity to think and learn about collaboration through active involvement in a collaborative process. Although the course was challenging, demanding and at times intensive the students worked well as groups and met all specified targets on time. They produced high quality materials in terms of both their own written work and the review of work written by others and the group process appears to have been largely open and positive. The developmental approach used gives students early and multiple-perspective feedback on their progress and provides confidence to build their work to higher levels than some individuals would normally achieve. One student, newly returned to education after some time in the workforce commented that she found the course 'exhilarating' and other students felt that the course had been a good and useful experience.

The current delivery (Term 4, 2002) has forty- five students groups comprising nine groups each having three internal students working with two external (distance) students. The manila folders used for managing the review process have been replaced by electronic folders and e-mail and web-based discussion facilities are used to support the internalexternal dialogue. We have not yet finished this course but feel that it appears to work well in this new mode, justifying the extensive planning of the structure of the previous internal only version.

Over time it is hoped that web-based software tools will be built into the course to better facilitate the collaborative process and to further build on the opportunity afforded by having external and internal 
students working together as collaborative groups. It is quite likely that, in the future, students in other time zones will become part of this course, thus adding a new and challenging dimension to the learning process. In conclusion, one student summarised the general feeling about the educational value of the collaborative experience offered by this course when they commented that:

'The mark was probably the same. But the experience and lessons that I got from this work are completely different. I worked with other people, learnt how to compromise and accept, convince and negotiate and contribute to a common goal.'

\section{References}

Davidson, N. (Ed), (1990). Cooperative Learning in Mathematics: A handbook for teachers. Addison-Wesley, USA.

Janis, I. L. (1971). Groupthink. Psychology Today, November, pp 43-46.

Johnson, R.T. \& Johnson, D.W. (1986). Action research: Cooperative learning in the classroom Science and Children, 24(2).

Johnson, D.W., Johnson, R T and Smith, K A. (1991). Active Learning: Cooperation in the College Classroom. Edina, NIN: Interaction Book Co., 1991, 1:19-20.

Miller, J E, Trimbur, J and Wilkes, J M. (1994). Group Dynamics: Understanding Group Success and Failure in Collaborative Learning. In Bosworth K and Hamilton S J (eds), 1994, Collaborative Learning; Underlying Processes and Effective Techniques, Jossey-Bass, USA.

Parker, R. (1984). Small group cooperative learning in the classroom, OSCC Bulletin, 27(7).

Rau, W and Heyl, B S. (1990). Humanizing the college classroom: collaborative learning and social organization among students, Teaching Sociology.

Vygotsky, L. (1978). Mind in society: The development of higher psychological processes. Harvard Un iversity Press.

\section{Biography}

David A Banks is a lecturer in the School of Accounting and Information Systems at the University of South Australia. He currently manages two courses, 'Collaboration and E Commerce' and 'Information Systems Development Methodologies'. Prior to joining the University of South Australia he worked at a UK university for twelve years after having spent sixteen years working with voice, data and video systems for a large UK telecommunications organisation. His research interests are in the areas of IS education, group process support systems and project management. 